\title{
Applications of Building Information Modeling methods in Risk
} Management and TimeManagement

\section{Mohamed Amr Sayed Hassana, Aly Fathy Eaid b, Hazem Mohamed Talat Eldaly ${ }^{c}$}

\author{
${ }^{a}$ Master Student, Dept of Architecture, Faculty of Engineering, Ain \\ shams university in Cairo, Egypt \\ ${ }^{\mathrm{b}}$ Professor. Dr, Dept of Architecture, Faculty of Engineering, Ain \\ shams university in Cairo, Egypt \\ ${ }^{c}$ Professor. Dr, Dept of Architecture, Faculty of Engineering, Ain \\ shams university in Cairo, Egypt
}

\begin{abstract}
The construction industry represents a major factor in the development of countries. And since it has a great impact on the livelihood and wellbeing of mankind, there was an urgent need to use better sophisticated methods to improve the efficiency of this industry.

And since there is a great importance to finish the project construction operations within the specified period of time, it was necessary to choose modern methods to solve this problem. It was also necessary to know the factors affecting the time, and try to make those factors work better by using that modern method. One of these factors which affect time is risk management, which will be studied in the research.

Building information modeling is considered as a modern and advanced method that has been applied in many countries to improve the efficiency of construction operations. As it has a great impact on time management for projects through the fourth dimension (4D).Also BIM can be used as a complete and integrated system in the construction processes, which leads to improved risk management for the project, and thus improved time management for the project.
\end{abstract}


Thus, this research work is concerned with studying two departments of the projects, namely, time and risk management. It also explains the relationship between them and how risk management affects time management, and then studies how BIM is used in these two managements to improve them.

In addition, practical studies are carried out on projects in which BIM has been used, and a comparison is made between the effect of BIM methods and regular methods on project time.

\section{Keywords:}

Time Management - Risk Management - Building Information Modeling - Building Information Modeling Fourth Dimension (4D) - Building Information Modeling Detail Level (LOD)

\section{INTRODUCTION:}

There is no doubt that BIM has recently spread all over the world. And it is used in construction projects widely. But despite that spread, and the increase in awareness of it in Egypt, its actual use in projects in Egypt is still limited. Therefore, it needs more planning to beused on its wide range and full potential.

Since there is importance for completing construction projects on its time, it was necessary to study BIM and its ability to influence the time management. And the effect of BIM on risk management is also being studied, due to the importance of the effect of that administration on time management.

\section{MATERIALS AND METHODS:}

\subsection{Definition of Building Information Modeling:}

It is an integrated system that includes everything related to the project. It is also considered a central database that feeds all project parties and contains all project documents, whether they are plans, specifications, tables of quantities, or the timetable for the implementation of project works. It also provides users with accurate information on all project phases and what functions are needed to complete the building through a virtual simulated model (Edde N, 2011). These systems have become commonly used by project parties 
during its life cycle by owners, designers, contractors and project managers as shown in Fig.1.

\section{We can also find a number of BIM definitions, including:}

1- BIM: It is an organized and coordinated set of processes that are supported by technology that adds value to it by creating, managing and sharing project characteristics during its life cycle (Hymas, D, 2012)

2- BIM: It is the process of generating and managing data related to the building during its life cycle. Building information modelling methods are used in the third dimension, time and simulation programs to increase productivity in the design phase and the construction phase. (McNell, D., et al. 2011)

\subsubsection{The genesis and development of BIM:}

The 3D space used for modelling was developed based on geometric modelling and 3D shapes in the late 1970s and early 1980s. It was difficult for users to use the early modelling software because they used two-dimensional modelling tools, and the computers available at the time were often not robust to meet the needs and support those processes.

Manufacturing needs prompted the creation of more useful modelling tools using information based on modelling elements. As a result of the growth in computer speed and the memory used in it, designers and implementers have begun to apply BIM to create integration between the various components of a building.

In the past decade, the tools available to the architecture, engineering, and construction industries have been able to link connected components into information and define their area around the component being modeled as shown in Fig.2. (Dinesen E, Thompson, 2010). 

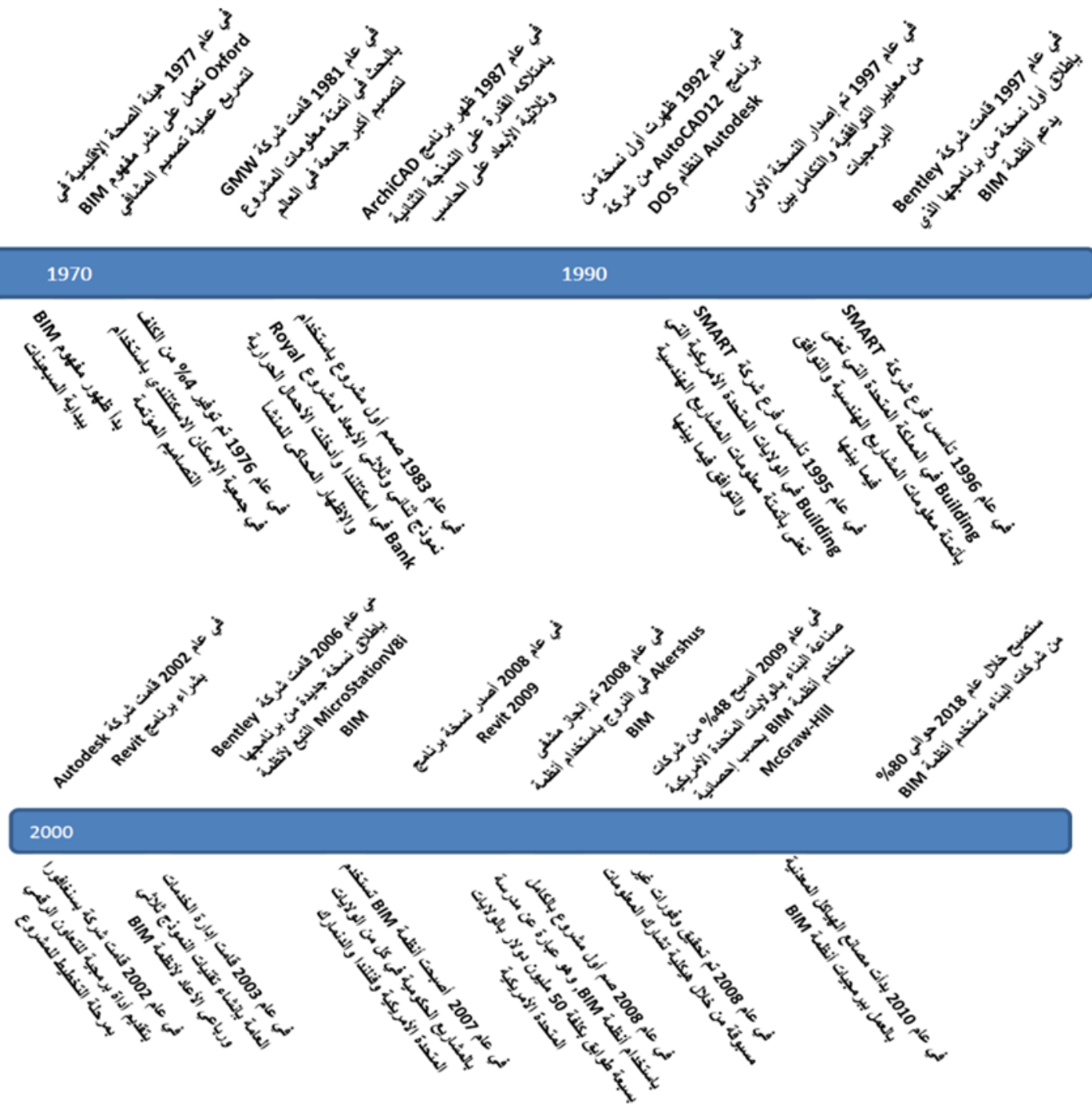

\section{Fig.2 Timeline of BIM development}

\subsubsection{BIM maturity levels:}

According to British standards and codes, BIM has gone through four levels, from its emergence to the current period (as shown in Fig.3):

Level 0: It is the pre-stage of BIM:

In which the CAD program was used to create drawings using a computer. 


\section{The first level: it is the stage of modeling work:}

At this level, we started by adding unified information and standards for two- and three-dimensional drawings, and most companies fall into this level.

\section{Second Level:}

This is the minimum required in Britain by 2016, when dealing with various programs is opened. Information models are also being built here to model building information and share information with other disciplines, but it does not necessarily mean working on one unified model. And at this level it is possible to work on the 4D and 5D.

The third level: it is the fully integrated project information modeling stage:

At this level, the entire project is placed in a shared data environment, so information can be exchanged by all project team members in real time. The companies that achieved this level were able to benefit from strategic advantages such as the least amount of waste and the delivery of the building in the least time. (BIMARABIA 3, 2015)

Figure 1 Core maturity model

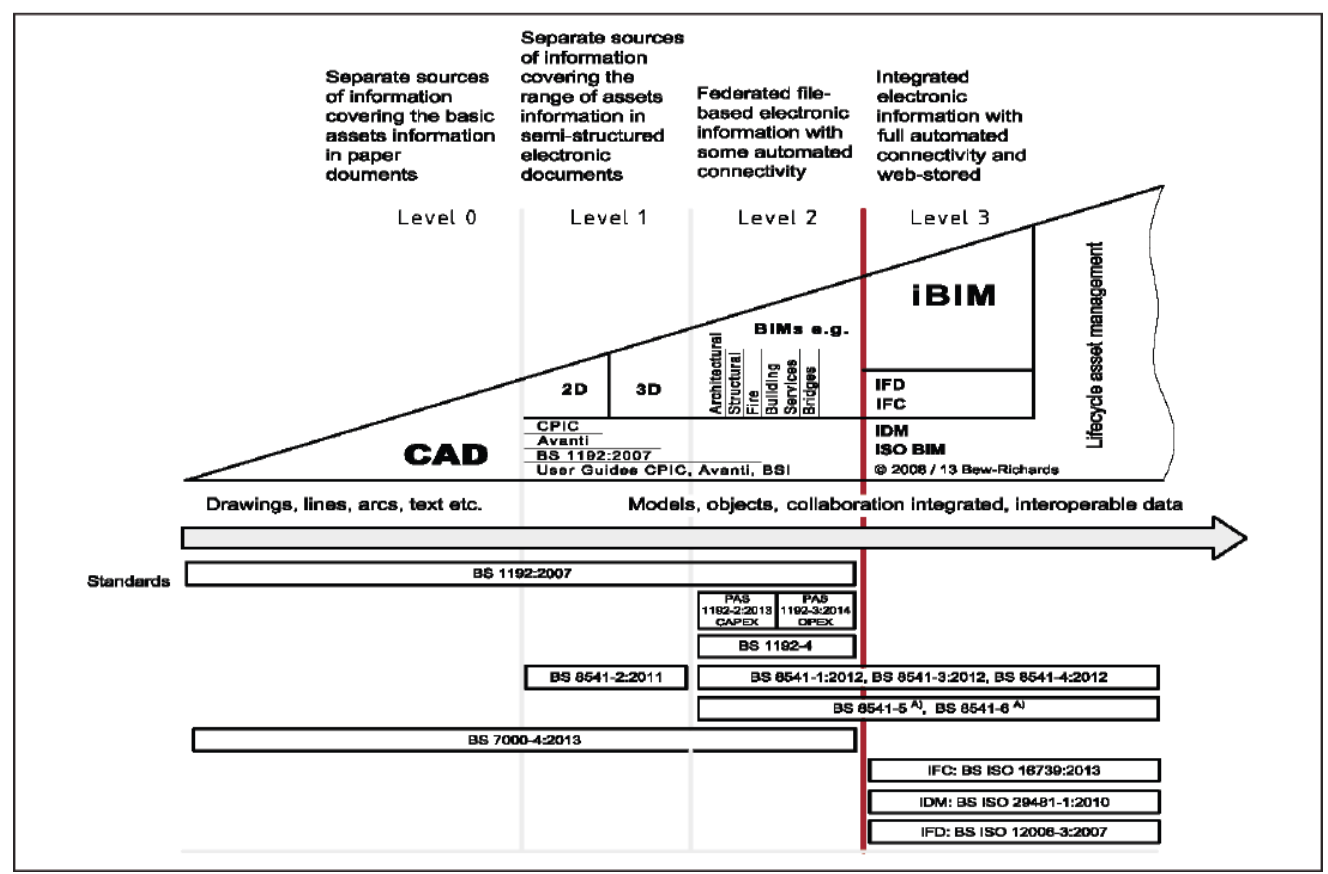

Fig.3 BIM maturity chart as per UK government strategy 


\subsubsection{The importance of BIM for project parties:}

BIM is used by all project parties to achieve technology goals, obtain its benefits, and stand against obstacles that may face the project or face the BIM process that can prevent engineers from reaching their goals from using BIM. (Smith J, 2012)

BIM helps to communicate between stakeholders to visualize the project model, and to easily understand their role in the project. Also, the contractor seeks to present his work during the bidding phase, and thus the expected method of building the project and its considerations during the design phase must be taken as planned. This will also include a preliminary offer of the available prices that will suit the contractor and project objectives. Therefore, by modelling building information, all this information can be visualized in advance through modelling and simulation. (Smith J, 2012)

It also helps the contractor to understand the designers' work so that he can provide the designer with the required data about the project so that the process of alignment between the design and construction stages occurs. It also contributes to the contractor's quantitative examination step, which will lead the contractor to more detailed and accurate quantities of project elements. (Smith J, 2012)

Owners who try to implement BIM have found that they get higher quality, performance, and other benefits in their projects, as a result of the fact that they define the organization's goals for the future using modelling in the market. Also it measures the progress of the project, used to manage the facilities, and increases the performance of the building by saving energy and lighting. It is also used to shorten the pre-fabricated design and coordination time which reduces field work time. (Eastman, 2011)

Modelling assists designers in estimating cost, designing the construction system, analysing, simulating and auditing, drawing and producing documents, making specifications, and integrating design and construction stages(Eastman, 2011) 


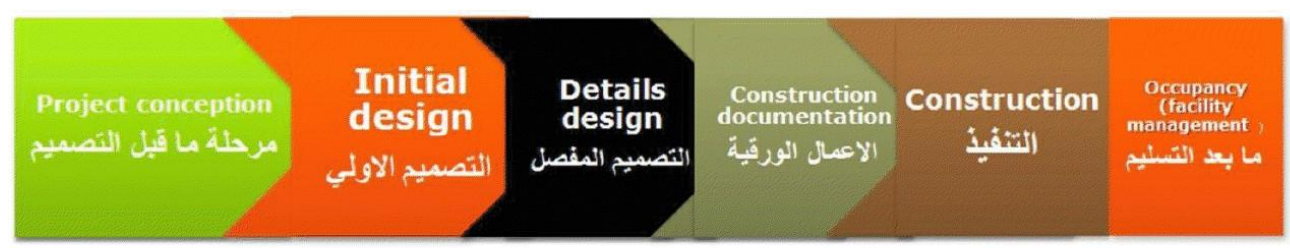

Designer pasil

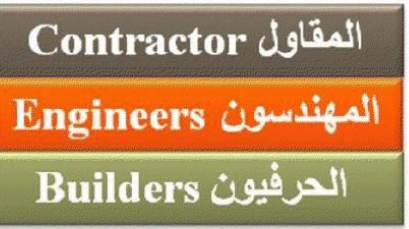

Owner stifli

Fig.4 project parties use the BIM throughout the building's life cycle

\subsubsection{Dimensions of BIM:}

BIM includes 8 dimensions, and for each dimension its use in the construction industry. And so far, new dimensions of BIM are being discovered. ("Building Information Modelling",2012).

$2 D$, which includes height and length where we can realize flat drawings for construction project.

$3 D$, in which we add the Width dimension to get a more realistic picture of the building. This level of dimension reduces risks that may occur, reduces rework and delays, and provides more accurate data. (Rundell, R., 2006)

$4 D$, where the time dimension is added to the $3 \mathrm{D}$ model to create a four-dimensional model that can be used to describe the project through its schedule and study alternatives and provide the ability to see the actual progress of the project on the model with the chronological progress of the project. ("Building Information Modelling", 2012) 
$5 D$, through which the cost dimension can be added to the 4D model to produce the 5D model, which is used in extracting an accurate cost estimate for the project by clarifying (quantities of materials, number of labour required, and number of period required to deliver a project). ("Building Information Modelling", 2012)

$6 D$, through which it is possible to conduct analyses and study the rates of energy consumption and even study the possibility of establishing green buildings that are environmentally friendly and avoiding operating through the active commercially purchased energy by moving towards adopting renewable natural energies as much as possible to operate the building and economize energy consumption in the long term to reach Zero point in carbon production. (BIMARABIA 19,2017)

7D, which includes the integrity of the building during construction, after handover of the project and through the asset management of the building.

$8 D$, which concerned with occupational safety in the construction sector.

Although there are 8 dimensions here, but it is not the end of BIM methods, as we mentioned earlier, it developed from the second dimension, to the third dimension, then to the simulation and timeline dimension, then after cost, then after the environment and analyses, then after managing Facilities down to the dimension of the safety, and with the continuous development of modelling, other dimensions may appear in the future that meet more needs of the construction system. 


\subsection{Introducing project management, time and risk management:}

Project management is the Applying of knowledge, tools, skills and techniques to project activities to meet project requirements. (PMBOK-Guide-5th-edition)

The project management applies a set of operations, which are classified into five groups (as shown in Fig.5):

Initiation, which is the set of processes that are conducted to define a new project in an alreadyexisting project by obtaining a permit to start that project or that phase.

Planning, which are the processes that take place to define the overall scope of effort, define goals, and develop the course of action required to achieve those goals.

Executing, which is some processes which are performed to complete the work specified in the project plan to meet the project specifications.

Monitoring and control, which are those processes required for tracking, reviewing and controlling the progress and performance of the project, and identifying the areas that require changes to the plan, and the initiation of those changes.

Closing, which are those processes that are performed to terminate all activities in all project management operations groups to complete the project, stage, or formally contracted obligations. (PMBOK-Guide5th-edition)

Construction projects go through three main phases, which are the initial photography and feasibility study, then the engineering phase, which includes design, implementation and delivery, and the operation and maintenance phase. 


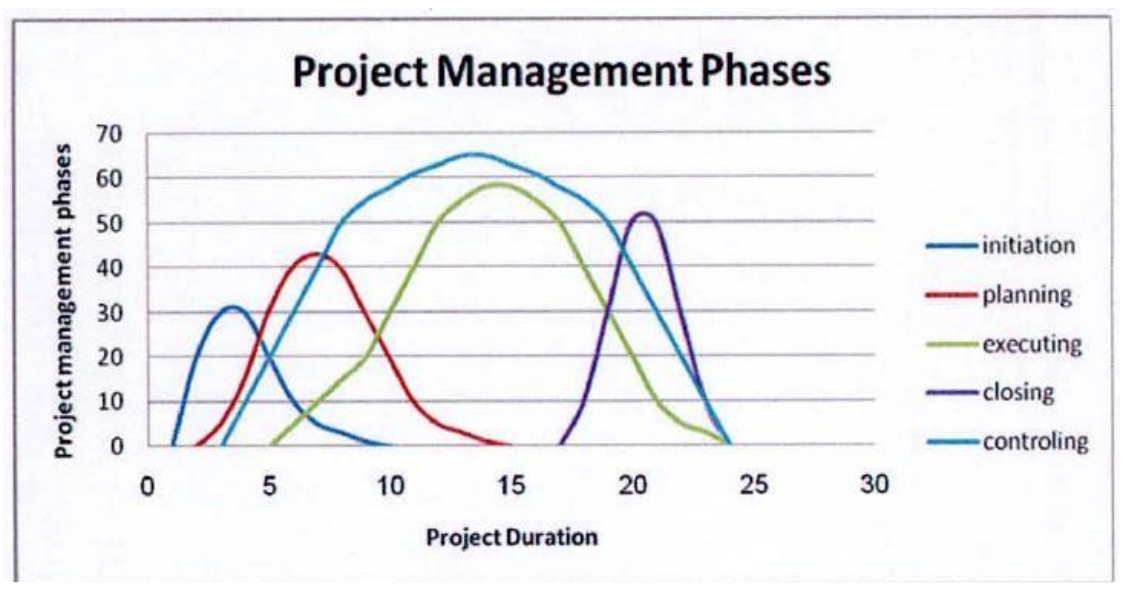

Fig .5 Project management processes overlap during project phases

\subsubsection{Elements of project management:}

There are ten departments, each field representing a complete set of concepts, terminology and activities that make up a professional field: Project Integration Management: This department contains a set of processes and activities that must be performed to identify, group and assign different processes and activities in the different groups of project management processes.

Project scope management: This department consists of the necessary processes to ensure that the project contains all the necessary processes to complete the project successfully.

Project time management: which are the processes related to completing the project on time, and it includes the processes of creating, developing and following up the timetable, and the processes of defining and following up the project activities and estimating their duration. 
Project cost management: which includes the processes involved in planning and estimating the cost of the project, budgeting, financing and managing it so that the completion of the project within the approved budget becomes available.

Project Quality Management: which includes the processes of determining quality policies, objectives and responsibilities by the implementing institution in order to achieve the desired objectives of the project.

Human resources management for the project (individuals): and it contains the processes thatorganize the project team.

Project Communications Management: which includes the processes required to ensure that project information is planned, collected, prepared, stored, controlled, and monitored.

Project risk management: which includes the processes of implementing plans to manage, identify, analyse, respond to and follow-up risks in the project.

Project procurement management (supplies): which includes all necessary operations to purchase and bring in products, materials, services, or necessary results.

Project stakeholder management: which includes processes that identify individuals, groups, orinstitutions that may affect the project, and analyse their expectations and their impact on the project.

These ten management relate directly to project management, as they affect each other directly, such as time management, which is directly affected by many departments such as cost management, quality management, people management, and risk management. (PMBOKGuide-5th-edition) 


\subsubsection{Objectives of project management:}

The project management aims to achieve the required quality in the project on time and at the lowest possible cost. (Cost, time, quality) (As shown in Fig.6). (Dr.Adel Al-Samadouni, 1995)

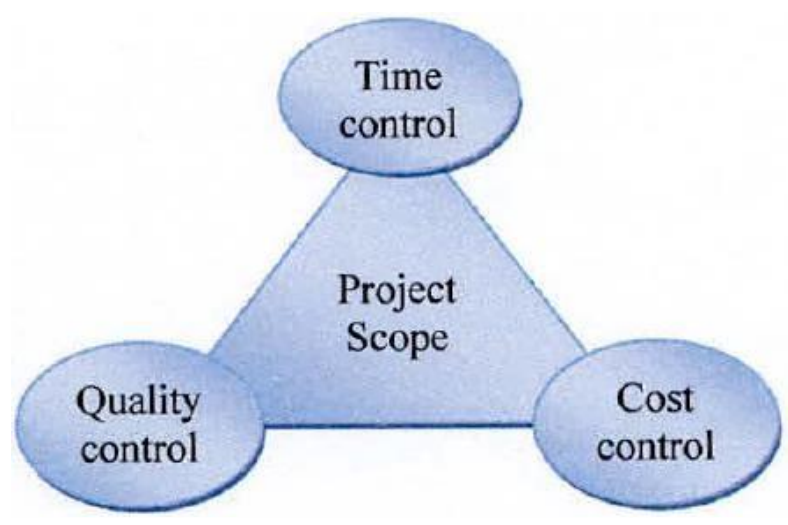

\section{Fig.6 Objectives of project management}

Each of these goals also affects the other, for example, when increasing the quality, this leads to an increase in the cost. Or if we want to reduce the time, this leads to an increase in labour and thus an increase in the cost, or if we want to reduce the cost, then this can affect the quality of the project.

\subsubsection{Definition of time management:}

Time management is defined as the set of processes needed to manage the timely completion of the project.

Time management includes several processes, namely: planning schedule management, determining activities, sequencing activities, estimating activity resources, estimating activity durations, developing the schedule, following up on the schedule. (PMBOKGuide-4th-edition) 
A timetable for the project is made with all its activities in order to ensure its completion on time, but it must be ensured that the project progress is monitored with the timetable, and the timetable is updated with the actual progress of the work in order to ensure the completionof the project on time and deal with any changes.

\subsubsection{The role of time management during the various stages of the project:}

Time management has an important role in construction projects. Not only in the implementation stage, but also in all project stages from the initial conceptualization stage, the feasibility study, and the project planning to the design stage, bidding, implementation, delivery, operation and maintenance.

\section{The role of time management during the initial conceptualization and feasibility study phase:}

It begins with preparing the initial scheduling of the project, in which the initial network planning for the activities is prepared, which contains the dates, the project owner's needs are met and the resources are placed in the proposed timetable.

The role of time management during the planning phase of the project: the basic rules for the timetable and the duration of its implementation are in this stage. An initial system for project follow-up is established. And this system contains reports that show the actual status of the project in terms of supplies, drawings, progress rates, the master resource plan, delivery reports and approvals.

The role of time management during the design and tender stage: project specifications are prepared at this stage.

The role of time management during the implementation phase: the contractor carries out its time programs after studying the logical sequence of the project's items, activities and the overlap of those activities with the work of schedules of resources and funds needed for the project. And there is control over the chronological progress of the works. 
The role of time management during the operation and maintenance phase: Maintenance plans are made regularly for all elements of the facility. Dates are set based on the technical specifications in each item. All these appointments are placed in a specific timetable with theappropriate financial plans for maintenance.

\subsubsection{Time management processes:}

It is represented in seven-time management processes (Egyptian Construction ProjectManagement Code, 2009)

The timeline management planning process, which is the process that defines the policies, procedures and documents needed to plan, develop, manage, implement and control the project's timeline.

The activity identification process, which is the process of identifying and documenting the specific procedures that need to be carried out in order to produce project deliverables.

Activity sequencing processes, which is the process of identifying and documentingrelationships between project activities.

The process of estimating activities' resources, which is the process of estimating the type and quantities of resources, human resources, equipment or supplies needed to implement each activity.

The activity durations estimation process, which is the process of estimating the number of work periods needed to complete individual activities using the estimated resources.

The timeline development process, which is the process of analysing the sequence of activities, their periods, their resource requirements and the constraints on the timetable in order to create a project timeline model. 
The timetable follow-up process, which is the process of monitoring and updating the status of project activities and controlling changes occurring on the reference line of the timetable in order to ensure the success of the established plan.

These processes consist of three stages: inputs, tools and methods and then outputs, Which provides each process what it needs in order to do its job.

\subsubsection{Definition of risk management:}

To define risk management, we must first define the word risk which is the possibility of an adverse deviation from the desired or desired result. (Tariq Hammad, 2003).

Thus, we can define risk management as an attempt to identify potential threats to the organization and the likelihood of their occurrence (McNamara, 2008)

Risk management includes a set of processes, namely, identifying risks, analysing risks, reducing risks, monitoring and controlling risks. (Hossen, 2006)

Identifying risks, which aims to identify all types of potential risks that the project may beexposed to.

Risk analysis, which is a process designed to eliminate or mitigate the effects of risks that threaten the achievement of the objectives of the project. They are divided into two basic stages after identifying the risk areas in the project:

Qualitative analysis, focusing on introductory and objective risk assessment.

Quantitative analysis, focusing on the estimated and statistical perspective and impact of risk. 
Reducing risks, which the effects of risks are reduced by taking the necessary measures.

Follow-up and control of risks, which can be defined as the measures that are taken to ensure the efficiency of business management and reduce errors.

\subsubsection{The importance of risk management to the project manager and its impact on projecttime and cost:}

Risk management is the way to identify all future challenges that may affect negatively orpositively the progress of the project.

Negative risks are the most dangerous that may stop or delay the project for various reasons depending on the type of project. So it must be determined by the degree of its occurrence and the degree of its impact on the project. And then determine the mechanism for dealing with it when it occurs, either by circumventing it, accepting it, or mitigating its effects.

As for the positive risks, they are an assistant factor for the project manager, for example lowering the prices of some materials which may help him save some sums and expenses and use them elsewhere in the project.

At the beginning of any project, any risks that may affect the project must be identified and arranged in terms of affecting the project from the top, medium and low. And plans must be drawn up to avoid these risks. 


\subsubsection{Types of risks that contracting companies are exposed to during the different projectphases:}

The risks to which the project in the contracting company is exposed to are divided intotwo main types. (Prof. Atef Abdel Moneim, 2000)

\section{Internal Risks:}

These are things that the project team can control or influence, such as: risks arising fromfaulty initial studies of the project, risks related to design processes, risks arising from the work team, mismanagement of the project, risks associated with construction operations and delivery risks.

\section{External risks:}

They are things outside the control or influence of the project team, such as: risks arising from failure of devices and equipment used in the project, risks resulting from technology, environmental risks, social risks, economic risks, financial risks and credit risks.

\subsection{Use of BIM in time management for construction projects:}

The 4D of modelling is used in project time which is called building model simulation. It can be defined as a simulation of the sequence of implementation of the construction activities required to complete the project, that is, a simulation of the timeline, as shown in Fig.7. (BIMARABIA 19,2017)

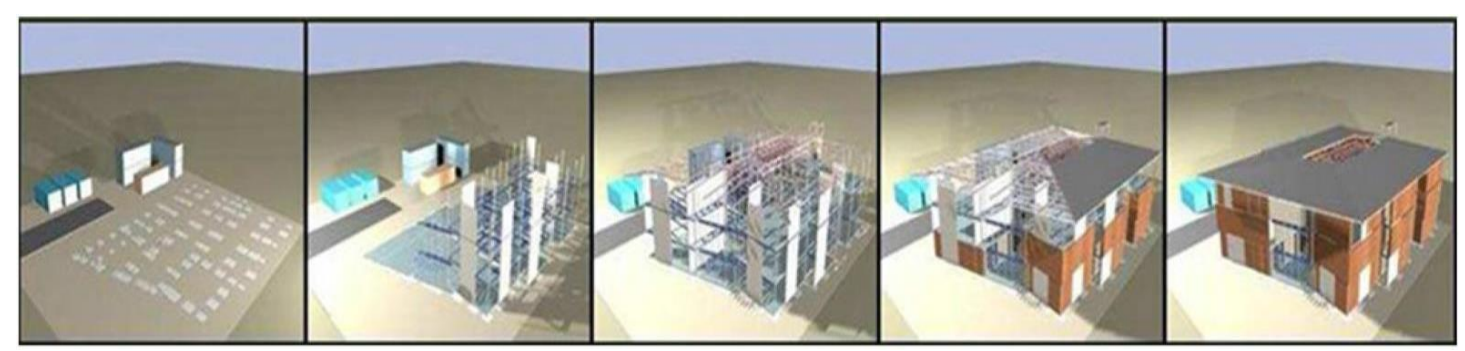

Fig.7 Simulation of a building model 


\subsubsection{History of the 4D of modeling:}

The concept of simulation construction did not get much attention until the late 1960s, at which time the process of linking the engineering drawings and the project implementation plan began, but it was simplified.

Then the simulation methods began by introducing new concepts, the first of which was the simple network. Then the first practical application of these methods was made, which is called (Line Node), which was applied by the engineer (Teicholz) in 1963. Then, engineer Halpin, in 1973 AD developed the concept of (Cyclone Format), which became the basis for a number of independent simulation programs. Then work continued on developing and introducing new concepts until the year $1990 \mathrm{AD}$, when (Halpin) developed the (MicroCYCLO) program, which was the first building simulation program to be developed, as shown in Fig.8. Then many simulation programs were developed until we got to the current time programs. (BIMARABIA 19,2017).

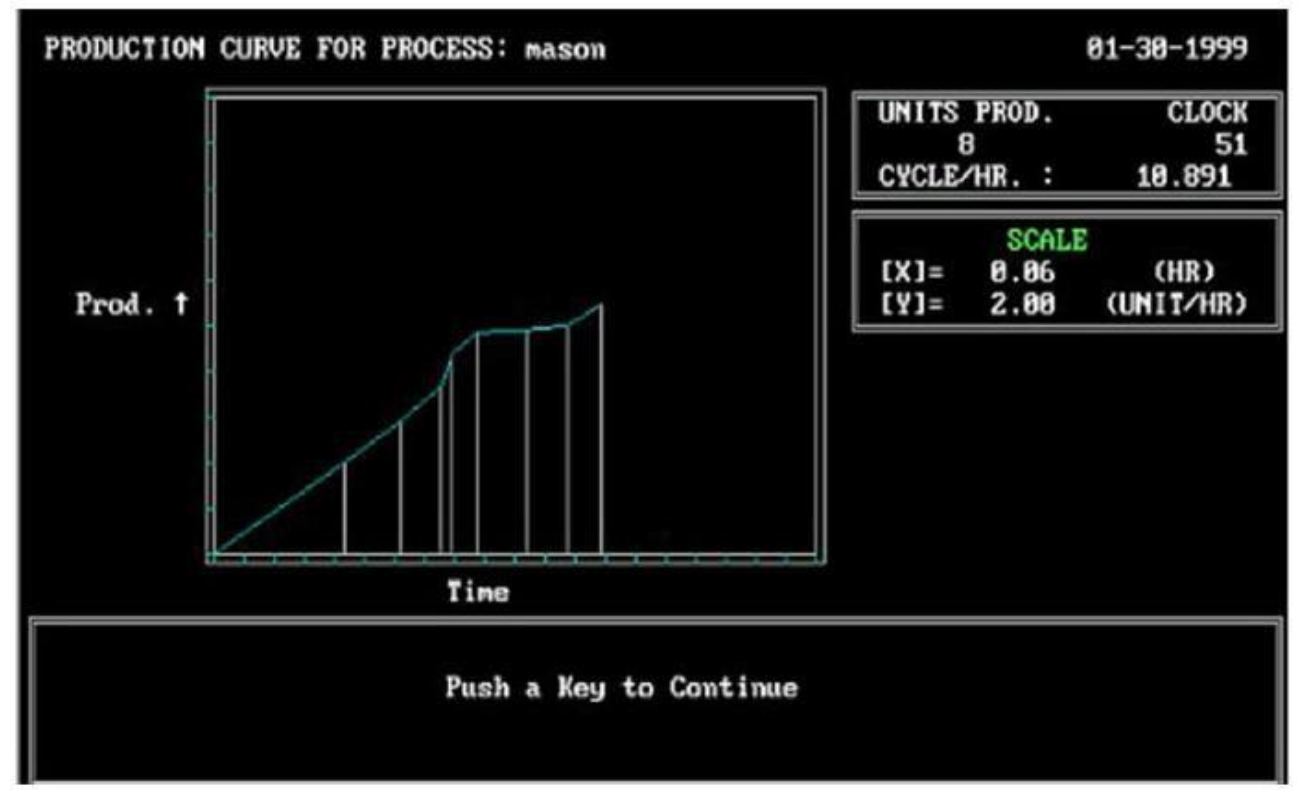

Fig.8 MicroCYCLO simulation model 


\subsubsection{Workflow map for creating a building simulation model:}

1- Obtaining 3D model from the design team and the timeline from the planning team.

2- Re-dividing each element in 3D model so that it corresponds to the corresponding activity in the timetable and re-classifying each activity according to the nature of the activity's work.

3- Linking each element in the triple model to the corresponding activity in the timeline. And the linking of each element is manual or automatic through a joint (CODING System) work between the design team and the planning team.

4- Ensure that the simulation process was done correctly.

\subsubsection{Benefits of the 4D of simulation:}

The benefits of the 4D are unlimited, because its use varies according to the nature of the project, but there are general benefits, including:

1- Increase the efficiency of the schedule and verify the correctness of the sequence of activities and methods of implementation.

2- The ability to analyse the implementation of activities in the timeline.

3- Helping in decision-making and evaluating it.

4- Improving the use of spaces in the general site and determining the general shape of the site during the implementation phases of the project.

5- Improving communication between all parties participating in the implementation of the project. (BIMARABIA 19,2017) 


\subsection{Use of BIM to manage risks for construction projects:}

One of the factors most capable of success or failure of any construction project is the accuracy of assessing the risks associated with this project and how to deal with it. With the development and introduction of BIM processes, methods of assessing and managing risks in projects have taken an additional dimension to the traditional ways of doing so. (BIMARABIA 10,2017)

BIM is of great importance in solving the project risks that were mentioned before (internal and external risks) because modelling is included in all project phases and details through its various dimensions (the second, third, fourth, ... etc.) In which it need to have all the data and information in an accurate and correct way in order to implement these dimensions in a correct manner. And it is the one that is originally the reason for the existence of these problems (data points and poor organization).

But there are some detailed risks facing the projects that use the modeling system. And some of their solutions are mentioned: (BIMARABIA 10,2017)

1- Lack of evidence to support supply chain expertise in modelling projects. It is solved by holding training courses for the supply chain at their various levels or by appointing an expert inmodelling.

2- $\quad$ Not updating the three-dimensional models due to changes in design or lack of cooperation between the parties. It is solved by checking the validity of the designs on a scheduled periodical basis, or by creating a tight and monitored system periodically to record the exit of forms, boards, emails, information and documents of all kinds transmitted / circulating within the shared data environment.

3- Wrong transfer of information, and consequently errors of construction work on the site. The solution is done by using (NBS Digital Toolkit) for organizing and conducting business and project detail elements. 
4- Corrupted files and inaccurate technology (software, scanners, etc.). The solution is to review the information inside the $3 \mathrm{D}$ models after exporting files, especially using or backing up data in safe and dispersed places.

Thus, although there are risks to using BIM in the construction industry, it eliminates many of the risks faced by projects that use traditional methods. Rather, with good study and gaining experience in modelling systems, the risks resulting from this method will be reduced with increased benefits because, as mentioned previously, BIM methods are endless methods and solutions for construction projects that work to increase the efficiency of projects with thelowest cost and less time, and it is originally the goal of managing Legislators.

\subsection{Applied study:}

Five projects were studied and analyzed in which BIM methods were used: Abu Dhabi International Airport building, Jeddah Cornice Hotel, New Al Sabah Hospital in Kuwait, Al Wafra residential complex in Kuwait and the New Egyptian Museum.

Then, a study and analysis of a project that used traditional methods was the building of housing for doctors and nurses at the University of Aleppo, Syria.

In the end, a comparison was made to clarify the effect of different BIM methods from thetraditional methods

The following is a study and analysis of one of the building information modeling methods projects, which is the Abu Dhabi International Airport Midfield Terminal Building. 


\subsubsection{Abu Dhabi International Airport Midfield Terminal Building:}

The project is located in Abu Dhabi, with a building area of 700,000 square meters and acost of $\$ 3$ billion, and thus it is considered one of the mega projects

The project consists of: an airport infrastructure with 106 gates, and main buildings of hotels, restaurants, shops and small internal buildings, as shown in Fig.9.

Main consultant is SOM. Architectural consultant and designer is KPF. Bentley and Nevis Work software have also been used.

\section{Level of development for the project life cycle: (LOD)}

Level (100): The role of the consultant is not mentioned. Whereas, the data received about the case study begins with the role of a contractor. But, in general, the processes that are not mentioned in the case study and that are concerned with the conceptual design that was developed after the feasibility study and the development of a project program include the scope and budget of the project, the needs and functions of the users and provide a briefoverview of the project.

Conceptual design establishes the project concept followed by a detailed and practical project design.

1- Level (200): The project consultant begins his role through the conceptual design work at the beginning of the project. Then the tender stage takes place to select the contractor whowill in turn create the IFC model. (IFC) 
- At this level, the financial institution model will be started only in preparation forcompleting it at level (300).

- This level also contains the schematic design of the project. Schematic design is the first stage of the basic services for project design. At this point in the project, the design specialist describes the 3D. A range of alternative design concepts are explored to define the nature of the completed project and the optimal realization of the project program.

- The next step after selecting the contractor, the consultant finishes the design of the project and the owner signs the contract with the contractor for the project, which will be the starting point for the contractor to start applying for his role in the construction contract and modelling operations.

2- Level (300): At this level, the International Finance Corporation form must have beencompleted. The contractor should also receive the detailed design and shop drawings.

During the design development phase, the project design is further refined. The plan arrangements and spaces for space, equipment, furnishings, building design, materials, colures, and complete definitions for all systems serving the project are being developed. All design decisions are finalized during this stage in order to prepare subsequent construction documents.

3- Level (400): The materials and logistical model must be created between levels (300 and 400). Then the building model, business model and systems integration must be created by the contractor at level (400), in order to bring the construction phase to level (500).

4- Level (500): Level (500) must include the delivery of the project in which it contains thefollowing requirements for the project:

Actual project drawings as built on the ground, facilities management, asset management, project operation and maintenance. 


\section{2- Deliverables of the various Building Information Forms for the project:}

\section{D model submission:}

All the traditional methods used in projects are two-dimensional models. These are the only visual models used for the building. Engineers use it to draw each required section of the site separately, as it is used to draw drawings for each system (structural, architectural, electromechanical, etc.) separately, and thus this type causes many errors that appeared laterduring the construction phase.

Also, the two-dimensional model deals with the elements as lines. But 3D model works with line as an element that has its properties and dimensions, and deals with it as a real image.

Therefore, the contractor receives 3D model from the consultant and begins to deal with it in the construction phase. Any change to the site during the construction phase is updated to be transferred automatically to other systems to reduce errors that may occur during the construction process.

\section{2-Components of the elements:}

The contractor begins to extract some required data about each component of the projectfrom 3D model.

The exported data for any element of the model can be: material type, volume, unit of measure, etc. And that data is compiled into a table extracted from the modeling program.

Elements in 3D model can be identified by their codes so that each element has its own unique code that will be used for any update or for communication between different programs. 
Building elements can carry more than one material, so the modeling model can save all material and element data and distinguish between their quantities. Therefore, each material must be added in the items during the creation of the model to be used later to extract the quantities report.

\section{3-Report of interference and errors for BIM:}

After creating a three-dimensional model for each system present in the building (structural, architectural, electrical, mechanical ... etc.), one model is made that contains all of these systems together. Thus, the clash between the different systems can be detected to extract the clash report that carries all the clashes that were found during the interference to preserve them in the model and modify it with the best solutions. This helps the contractor overcome any expectation of errors coming on the site during construction and helps the owner reduce the waste in time and cost.

In Fig. 9, a clash was found between the structural model and the pile cap model. So there must be a solution to this clash which has been discussed between contractor and designer.

This illustrates the importance of BIM, which enables problem detection and solution prior toimplementation.

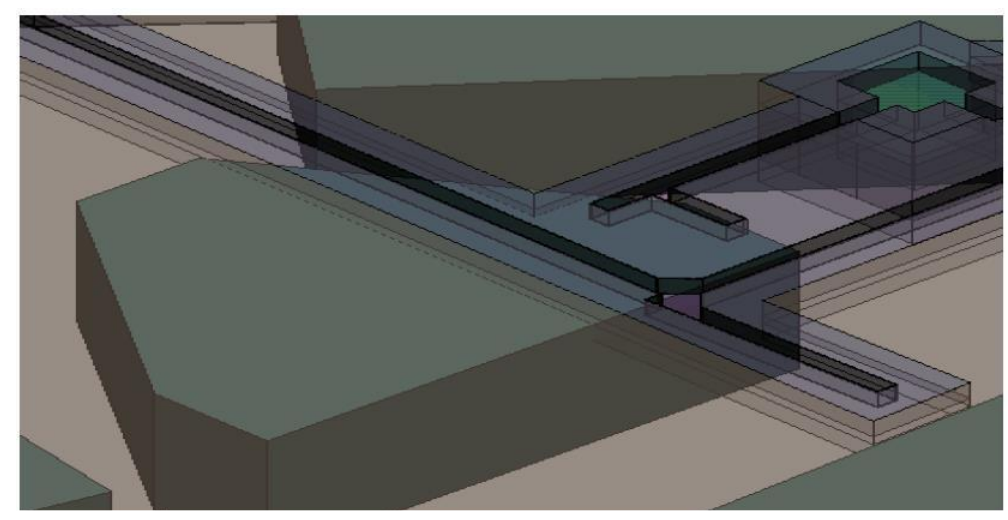

Fig. 9 the clash area 


\section{4-Simulation tables and 4D modeling:}

The four-dimensional model is a combination of $3 \mathrm{D}$ model and the time dimension in the project that can be used later to find out the work sequence in the site and move the cranes (crane plan) in the site to not interfere between different activities at the same time, as shownin Fig.10.

It can also be used to make a plan for storing materials on site according to the available work places on the site.

Benefits realized from combining 3D model and time in Abu Dhabi project:

1- Presentation of a broad and in-depth research in the project construction process (construction methodology).

2- Coordinated construction timetables between all systems.

3- Comply with the stringent requirements set for processing sensitive data.

4- Multiple clash reports depend on time.

5- There is more than one alternative and solution.

The contractor mentioned the return benefits of $4 \mathrm{D}$ model in his presentation at the second annual conference of BIM in Abu Dhabi as follows:

Key benefits such as full traceability of construction work on site, enhanced coordination between different disciplines, early adjustments to the timetable in compliance with project requirements and improvement of the construction phase.

Secondary benefits such as creating sustainable and environmental constructions, saving costs and assets, avoiding conflicts and reducing project construction time. 


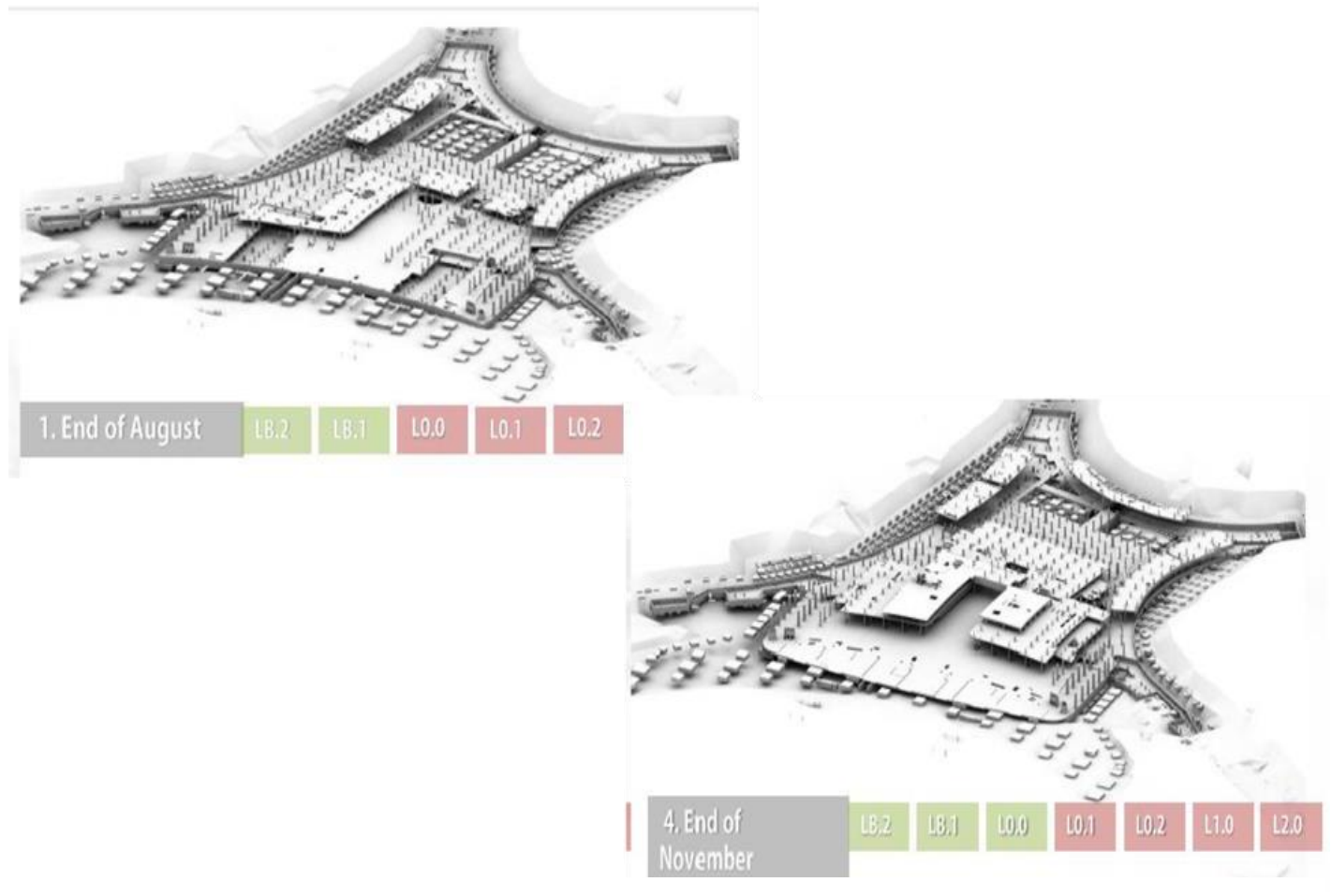

Fig. 10 An extract from the fourth dimension and the development of the project

5- Using modelling to organize resources and mobile equipment on site (site logistics):

The contractor thought in the airport project to use 4D model to organize the cranes and their movement across the site during the steps of establishing the project, in order to regulate the movement and location of the tower cranes during construction time according to the work sequence and the available places on the site.

The project included three sets of tower cranes:

Group (1): fixed tower crane installed on a temporary basis.

Group (2): tower undercarriage and fixed cranes. 
Group (3): fixed tower cranes were built in the middle terminal building and fixed on the covers of the existing pillars and the foundation of the pontoons.

The three groups of cranes were organized for their locations during the project life cycleaccording to the project schedule and 3D model.

Thus, it is evident from all the above the importance of using BIM methods in this project, as each of the modelling outputs solved and ended a large group of risks which the project would have faced if it were to be implemented by traditional methods. Thus, the completion of the project implementation in less time.

\section{RESULTS AND DISCUSSION:}

Through the previous study, the research reached a number of results related to the use of BIM. As the research clarified that the use of BIM in construction in Egypt is recognized as an important tool for the industry. The initial rendering and application are limited to the 3D model used in the visualization only. However, the modeling capabilities go beyond this limited use and can be applied to all project phases by entering all element data and using it to obtain the benefits mentioned before and not just for visualization.

Therefore, a study of the use of BIM in construction projects was conducted to verify three points: the use of modeling in projects, the benefits of using modeling in those projects and the obstacles to using modeling in those projects.

\section{The results can be summarized as follows:}

It was clear after reviewing the case studies that there is a fear of using BIM as a continuous process from the beginning of the project to the end. And the only agreed opinion is that it can be used to visualize the project in 3D. Indeed, modeling can be used in more than that in general and in reducing project time and reducing project risks in particular. 
1- According to the benefits used by the contractor and the consultant in the case studies presented, BIM proves its useful role in construction management. But it is still used on a small scale in Egypt with limited experience. So users of Egyptian companies still make mistakes when using them and they are reluctance to apply and popularize modeling in all their upcoming projects.

2- From the owners' point of view, modeling proves its importance in implementing and fulfilling the needs of the owner. So according to the construction market and the method in reducing errors and saving time, it is advisable to keep pace with the construction market and try to exploit the modeling methods in future projects in Egypt.

3- It was evident from the case studies that the construction project faces many errors during the design phase which may have an impact on the time, cost and quality of the project, which may lead to ineffective and disappointing results in the project. However, using some modeling features in the project phases from the start of the project will help avoid this mistakeand get a more efficient project.

4- It also became clear that $4 \mathrm{D}$ model saves a lot of time for the project. And from it we can control the resources and machines at the project site, how to move them in the project, and the appropriate times for them, which led to reducing project risks and time and providingsafety at the site.

5- These results support the findings of the study that was conducted at Stanford University on 32 huge projects, and it was found that $40 \%$ of sudden changes could be avoided during implementation (improving risk management and thus time management), accuracy in cost calculation reached $97 \%$, saving $80 \%$ of time required to calculate cost (improve time tool), save $10 \%$ of cost and reduce $7 \%$ of project time (improve time management). 
6- In the end, it is concluded from the studied cases that BIM is a complete process from the beginning of the project through its stages until the end of the project and after it is handed over to the owner. It also contributes to achieving a tight system to follow up the project's steps and to help the owner reach his goals. Since it became clear that BIM has a major role in the construction process, a number of steps (a plan) were made for how to use BIM methods in Egypt and apply them correctly:

1- BIM is used from the early stages of the project (initial conception and feasibility study), as BIM is an integrated process from the first stage of the project to the end which lead to Promote better results.

2- BIM is used in the planning stage by creating an appropriate database for the entire project, and the rest of the project's programs are entered into it such as safety, an initial system to follow up on the project and calculate the expected cash flows.

3- The various alternatives to the project are made and evaluated through BIM programs (the third dimension and analysis programs for BIM), then the work of time programs (the fourth dimension) and the cost of the project (the fifth dimension).

4- Bids, licenses and permits are submitted, then the contractor is selected and the contract is made which one of its clauses is that the BIM methods are the methods used in the project, and the rules for dealing with them are set in the project and how the project is monitored and updated.

5- Implementation stage, in which project management and the rest of the BIM dimensions overlap from simulation, cost, labor, safety, resources and equipment, where pre-made models are worked, in addition to updating them first, following up and writing everything in them to reduce risks

6- BIM also use in operation and maintenance phase. Even after the completion and operation of the building, the project data is preserved through specialized BIM programs, and follow-up and maintenance are carried out through these programs. 
7- There should be a BIM team in each team of the project in order to use the BIM methods in a correct way and not have adverse effects.

8- Do not leave any information without registering it in the BIM system at any stage of the project so that no risks occur in the project as a result of information loss.

\section{Recommendations:}

We recommend that this research study be implemented in Egypt as every country has itscapabilities to use a new technology. Therefore, this research is concerned with introducing BIM with its appropriate vision and knowing its feasibility to continue in Egypt.

\section{Therefore, future work is recommended for:}

1- Study the development of manuals for the rules for using BIM in Egypt.

2- Study how we can push the Labor market to use the BIM in all its stages and not only at the design stage.

3- Study the uses of BIM after handover of the facility.

4- The importance of studying BIM for engineers and all concerned in the construction sector. And explaining its importance and benefits to them.

5- Use BIM in designing prefabricated sections and building materials to save time and cost.

6- Study how to reduce BIM restrictions in Egypt. 


\section{References:}

(1) EDDE N., 2011 - Matering Autodesk Revit 2011. In:KRYGIEL E., READ P., VANDEZANDE J., ST., Wiley Publishing, United States of America.

(2) Hymas, D. (2012, April 26). "Building Information Modeling: The Designer". Construction Industry Concil and IDBE Master Programme.

(3) McNell, D., et al. (2011). "Building Information Modeling". InfoComm International. Retrieved from http://www.infocomm.org/cps/rde/xbcr/infocomm/Brochure_BIM.pdf

(4) DINESEN E., THOMPSON., 2010 - Constructing the business case Building information modelling., ST., British Standards Institution, UK.

(5) Smith J, (2012). " BIM-A contractors perspective" International Federation of Surveyors UK

(6) Eastman, C., P. Teicholz, et al. (2011). BIM Handbook: A Guide to Building Information Modeling for Owners, Managers, Designers, Engineers and Contractors. Hoboken, New Jersey, Wiley.

(7) "Building Information Modelling". (2012, April). Retrieved from Out-Law.com - Legal news and guidance from Pinsent Masons: http://www.out-law.com/en/topics/projects-- construction/projectsand-procurement/building-information-modelling/

(8) Rundell, R. (2006). "Building Design: 1-2-3 Revit: BIM and Cost Estimating, Part 1". CadalystMagazine

(9) Project management Body of Knowledge, 5th edition, Project Management InstitutePMI,2013 
(10) McNamara, C., (2008), Authenticity Consulting, LLC Copyright 2008.

(11) Hossen Fouzi A. (2006), Planning Risk Assessment in the Manufacture of Complex Capital Goods, PhD Thesis, Newcastle University, UK

(12) Construction Management, Dr. Adel Al-Samadoni, Dr. Hani AlSawah, Dr. Osama Ahmed Hassan, Faculty of Engineering Al-Matareya Branch, 1995

(13) The Egyptian Code Construction Projects, National Center for Housing and Construction Research, 2009

(14) Risk Management, Tarek Abdelali Hammad, University Youth Foundation, Cairo, 2003

(15) Evaluate risk management, a. Dr. Atef Abdel Moneim - Prof. Dr. Mohamed Mahmoud Al-

Kashef, Mars Publishing and Distribution House, Cairo, 2000

(16) Beam Arabia Magazine, Issue No. 3, 2015

(17) Beam Arabia Magazine, No. 10, 2016/(18) Beam Arabia Magazine, No. 19, 2017

Received: April 2021

Accepted: June 2021 